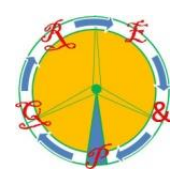

\title{
Evaluation of Medium Voltage Distribution Network with/without Distributed Generation using ATP Software
}

\author{
J. O. Rezende ${ }^{1}$, L. M. Peres ${ }^{1}$, G. C. Guimarães ${ }^{1}$, A. J. de Moraes ${ }^{1}$ and M. A. Tamashiro ${ }^{1}$ \\ ${ }^{1}$ Faculty of Electrical Engineering \\ Federal University of Uberlândia \\ Campus Santa Mônica - Uberlândia, Minas Gerais (Brazil) \\ Power System Dynamics Group \\ Phone/Fax number:+553432394758, e-mail: jaqueline.oliveirarezende@gmail.com, larissaa_mp@yahoo.com.br, \\ gcaixeta@ufu.br, ajmoraes@ufu.br, tamashiro@ifto.edu.br
}

\begin{abstract}
This research has as main objective to analyze the contributions of a distributed generation unit when connected to a medium voltage distribution feeder $(13.8 \mathrm{kV})$. The behaviour this electrical system is evaluated following the occurrence of some disturbances. Before this, all the modelling of the electrical system was performed using ATP - Alternative Transients Program. Three types of disturbances were simulated: phase-toground short-circuit, islanding of part of the electrical system and load increase on the feeder. To easy the comparisons, all studies were carried out with and without the presence of the distributed generator taking into account the following variables: busbar voltage profile, output power provided by the substation and by the distributed generator when present.
\end{abstract}

\section{Key words}

ATP software, distributed generation, medium voltage distribution network, output power, voltage profile.

\section{Introduction}

Electricity is an essential element for the development of various sectors of the economy. The demand for this resource has shown an impressive growth over the years. The main way to reach this demand is to use large power generating plants. This type of generation is usually located away from the centres of consumption. Thus, it is necessary to use the transmission and distribution systems to provide electricity to consumers [1].

Furthermore, the construction of large power plants needs to fulfil various requirements such as high financial investments, detailed environmental studies, among others. These factors often hinder the construction of new generating units and contribute to the delay in its accomplishment [2].

In this context, it is notorious that various sectors are seeking new ways to supply the demand for electricity.
Thus, one way of generation is the distributed generation (DG) and what is being widely researched. Many experts predict that the installation of these new sources of power generation will increase due to the need to provide more clean energy [3].

Distributed generation when compared to large power plants has as main features: location near to the consumer, lower construction time and lower energy distribution costs [4]. Moreover, the connection of distributed generation units contributes to postponement or reduction of investments in construction to reinforcement of the electrical system and also decreases the power demand from the electric company [5].

In Brazil, the distributed generation is regulated by Resolution $\mathrm{n}^{\circ} 482$ of 17 April 2012 and the Module 3: Access to the Distribution System, contained in PRODIST (Procedures for Distribution Network in the National Electric System), both under the responsibility of the National Electric Energy Agency (ANEEL). The first resolution establishes the conditions for access to the distribution system, the power compensation system, the energy measurements and the liability for damage to the electrical system [6]. The second treats the specifications for enabling access, project requirements, deployment of new connections, metering system, requirements for operation, maintenance and connection safeness and presents a contract model to adhere to the power compensation system [7].

Thus, this research aims to analyze the impact of a distributed generator connected to a $13.8 \mathrm{kV}$ feeder when disturbances occur in this system. The phenomena studied are phase-to-ground short-circuit, islanding of part of the electrical system and load increase on the feeder. To evaluate the distributed generator contributions, all the simulations are performed with/without the connection of the distributed generation unit in the electrical system. 


\section{Electrical System}

The electrical system analysed is from Bandeirantes Electricity Company whose data were taken from reference [2]. It is represented by a $13.8 \mathrm{kV}$ distribution feeder that starts from a substation and goes to feed six loads. Later, a distributed generator will be connected to the feeder to allow the studies proposed in this paper.
The software named "Alternative Transients Program" ATP - was used to perform the simulations. It requires an appropriate modelling of the data and parameters of the electrical system for using this software, as will be presented in the next section. Figure 1 shows the configuration of the electrical system studied with all data already represented in the ATP software, identifying the presence of a distributed generator (DG) equipped with voltage and speed regulators.

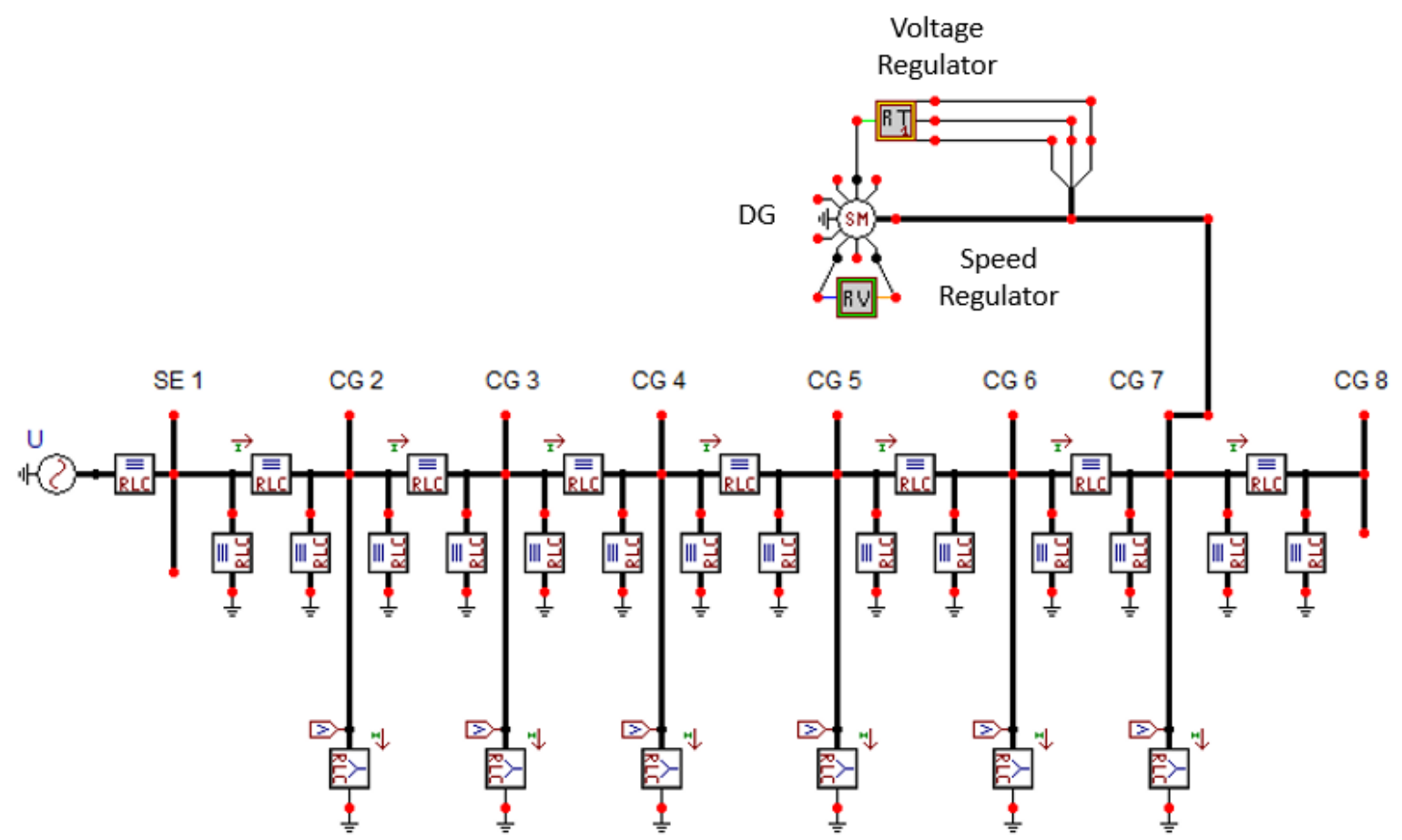

Fig. 1 Schematic of the electrical system in the ATP software.

\section{Modelling of Electrical System}

To represent the electrical system in the software ATP it was necessary to model all components of the system, as detailed below.

\section{A. Modelling of Substation}

The power substation was represented as a constant voltage source (infinite bus) in series with an inductance. The magnitude of the voltage source is the nominal rating value of the feeder $(13.8 \mathrm{kV})$.

A free computer software, called UFUFlow [8] for load flow calculations, was then used in order to determine the phase angle of the voltage source. The total active and reactive power values that come from the substation to the electrical distribution system were provided in reference [2]. These values are $7 \mathrm{MW}$ of active power and 2.3 MVAr of reactive power.

Thus, after running UFUFlow program, the value of the angle of the substation busbar voltage was determined to be $3.23^{\circ}$.

\section{B. Modelling of Loads}

The power demands of the loads were also taken from reference [2], which shows the values of active and reactive powers. These loads were represented in ATP by corresponding values of resistance and inductance (constant impedance). Thus, after the calculations, the values obtained for the loads can be seen in Table I.

TABLE I - Loads Values

\begin{tabular}{|c|c|c|c|c|}
\hline Bus & P[kW] & $\mathbf{Q}[\mathbf{k V A r}]$ & $\mathbf{R}[\mathbf{\Omega}]$ & $\mathbf{L}[\mathbf{m H}]$ \\
\hline CG2 & 870 & 275 & 193.86 & 162.52 \\
\hline CG3 & 800 & 255 & 196.51 & 166.16 \\
\hline CG4 & 1160 & 370 & 132.85 & 112.39 \\
\hline CG5 & 1260 & 400 & 121.48 & 102.28 \\
\hline CG6 & 470 & 150 & 323.83 & 274.14 \\
\hline CG7 & 2170 & 690 & 69.54 & 58.65 \\
\hline
\end{tabular}

\section{Modelling of Distribution Lines}

The lengths of the distribution lines for the modelling by ATP were also obtained from reference [2]. The conductor used in modelling is referred as CAA 336.4 whose technical data can be obtained directly from the manufacturer catalogue (Nexans [9]), which gives the following values for the resistance, inductive reactance 
and capacitive reactance, respectively: $0.2051 \Omega / \mathrm{km}$, $0.3770 \Omega / \mathrm{km}$ and 0.2266 M. $\Omega . \mathrm{km}$. By having such parameters, each distribution line can then be represented by the $\pi$ model which is described by its resistance and inductance arranged in series, and its total capacitance placed in parallel so that each half occupies one end of the line. The parameters obtained can be seen in Table II.

TABLE II- Parameters of Distribution Line

\begin{tabular}{|c|c|c|c|c|}
\hline Branch & Distance $[\mathbf{m}]$ & $\mathbf{R}[\mathbf{\Omega}]$ & $\mathbf{L}[\mathbf{m H}]$ & $\mathbf{C}[\boldsymbol{\mu} \mathbf{F}]$ \\
\hline SE1 - CG2 & 1000 & 0.2051 & 1.000 & 0.0117 \\
\hline CG2 - CG3 & 3000 & 0.6153 & 3.000 & 0.0351 \\
\hline CG3 - CG4 & 1000 & 0.2051 & 1.000 & 0.0117 \\
\hline CG4 - CG5 & 500 & 0.1025 & 0.500 & 0.0058 \\
\hline CG5 - CG6 & 500 & 0.1025 & 0.500 & 0.0058 \\
\hline CG6 - CG7 & 1000 & 0.2051 & 1.000 & 0.0117 \\
\hline CG7 - CG8 & 1000 & 0.2051 & 1.000 & 0.0117 \\
\hline
\end{tabular}

\section{Modelling of Distributed Generator}

The distributed generator used in the simulations is rated $5 \mathrm{MVA}, 60 \mathrm{~Hz}, 4$ poles. The other parameters of the generator were taken from reference [10] and can be seen in Table III. The model chosen in ATP to represent such synchronous machine was the SM59controlled type.

TABLE III - Parameters of Distributed Generator

\begin{tabular}{|c|c|c|c|c|c|c|c|c|}
\hline $\mathbf{H}$ & $\mathbf{X}_{\mathbf{d}}^{\prime}$ & $\mathbf{X}_{\mathbf{d}}$ & $\mathbf{X}_{\mathbf{q}}$ & $\mathbf{X}^{\prime \mathbf{d}^{\prime}}$ & $\mathbf{X}_{\mathbf{q}}^{\prime \mathbf{q}}$ & $\mathbf{T}_{\mathbf{d o}}^{\prime}$ & $\mathbf{T}_{\mathbf{d}} \mathbf{d o}^{\prime}$ & $\mathbf{T}_{\mathbf{q}} \mathbf{q o}$ \\
\hline 0.68 & 0.23 & 1.31 & 0.75 & 0.16 & 0.17 & 3.58 & 0.012 & 0.08 \\
$\mathrm{~s}$ & $\mathrm{pu}$ & $\mathrm{pu}$ & $\mathrm{pu}$ & $\mathrm{pu}$ & $\mathrm{pu}$ & $\mathrm{s}$ & $\mathrm{s}$ & $\mathrm{s}$ \\
\hline
\end{tabular}

\section{E. Modelling of voltage and speed regulators}

Voltage and speed regulators were represented in the software according to references [11] and [12], with the parameters obtained from reference [10]. These data can be seen in Table IV and Table V, respectively.

TABLE IV - Parameters of Voltage Regulator

\begin{tabular}{|c|c|c|c|c|c|c|c|}
\hline $\mathbf{K}_{\mathbf{a}}$ & $\mathbf{T}_{\mathbf{a}}$ & $\mathbf{K}_{\mathbf{f}}$ & $\mathbf{T}_{\mathbf{f}}$ & $\mathbf{K}_{\mathbf{e}}$ & $\mathbf{T e}$ & $\mathbf{V}_{\mathbf{m a x}}$ & $\mathbf{V}_{\mathbf{m i m}}$ \\
\hline $400 \mathrm{pu}$ & $0.02 \mathrm{~s}$ & $0.03 \mathrm{pu}$ & $1 \mathrm{~s}$ & $1 \mathrm{pu}$ & $0.8 \mathrm{~s}$ & $6.6 \mathrm{pu}$ & $0 \mathrm{pu}$ \\
\hline
\end{tabular}

TABLE V - Parameters of Speed Regulator

\begin{tabular}{|c|c|c|c|c|c|c|c|}
\hline Flyballs & $\mathbf{R e g}$ & $\mathbf{T}_{\mathbf{b}}$ & $\mathbf{T}_{1}$ & $\mathbf{T}_{2}$ & $\mathbf{T}_{3}$ & $\mathbf{T}_{4}$ & $\mathbf{T}_{5}$ \\
\hline $0.01 \mathrm{pu}$ & $0.05 \mathrm{pu}$ & $0.2 \mathrm{~s}$ & $0.3 \mathrm{~s}$ & $1.0 \mathrm{~s}$ & $1.0 \mathrm{~s}$ & $0 \mathrm{~s}$ & $0.1 \mathrm{~s}$ \\
\hline
\end{tabular}

\section{Electrical System in Steady State}

The first simulations were carried out to get the initial steady state conditions of the electrical system The results for voltages and power values are presented in Tables VI and VII present, respectively, with and without the presence of the distributed generator.

TABLE VI - Phase-to-phase and phase-to-neutral voltages

\begin{tabular}{|c|c|c|c|c|}
\hline \multirow{2}{*}{ Bus } & \multicolumn{2}{|c|}{ With DG } & \multicolumn{2}{c|}{ Without DG } \\
\cline { 2 - 5 } & Vline[k V] & Vphase[k V] $_{\text {pline}}[\mathbf{k V}]$ & Vphase $_{\mathbf{k} V]}$ \\
\hline SE1 & 13.80 & 7.97 & 13.80 & 7.97 \\
\hline CG2 & 13.76 & 7.94 & 13.62 & 7.86 \\
\hline CG3 & 13.68 & 7.89 & 13.17 & 7.60 \\
\hline CG4 & 13.68 & 7.89 & 13.04 & 7.53 \\
\hline CG5 & 13.69 & 7.90 & 12.99 & 7.50 \\
\hline CG6 & 13.72 & 7.92 & 12.96 & 7.48 \\
\hline CG7 & 13.80 & 7.97 & 12.91 & 7.45 \\
\hline CG8 & 13.80 & 7.97 & 12.91 & 7.45 \\
\hline
\end{tabular}

TABLE VII - Active and Reactive Powers for SE and DG

\begin{tabular}{|c|c|c|c|c|}
\hline \multirow{2}{*}{} & \multicolumn{2}{|c|}{ With DG } & \multicolumn{2}{c|}{ Without DG } \\
\cline { 2 - 5 } & P [MW] & Q [MVAr] & P [MW] & Q [MVAr] \\
\hline SE1 & 5.04 & 0.92 & 7.00 & 2.6 \\
\hline DG & 2.51 & 3.49 & - & - \\
\hline
\end{tabular}

\section{Case Studies}

Three case studies were performed in order to evaluate the impact of the disturbances on the distributed generator connected to a $13.8 \mathrm{kV}$ distribution feeder. To facilitate the comparisons, all simulation cases were also carried out without the DG presence.

\section{A. Phase-to-Ground Short-Circuit Case}

A solid phase-to-ground short-circuit was simulated since it occurs more frequently in the electrical system. Therefore, it was chosen a point located $300 \mathrm{~m}$ from bus CG5 and $200 \mathrm{~m}$ from bus CG6. The short-circuit was applied at phase C of line CG5 - CG6 shown in Figure 1. The short circuit started at time $2 \mathrm{~s}$. Table VIII shows the final steady-state values of the phase voltages (after ending of the disturbance) with the presence of the distributed generator.

TABLE VIII - Short-circuit case with DG: final steady-state voltage values

\begin{tabular}{|c|c|c|c|c|c|c|}
\hline \multirow{2}{*}{ Bus } & \multicolumn{2}{|c|}{$\mathbf{V}_{\mathbf{a}}$} & \multicolumn{2}{|c|}{$\mathbf{V}_{\mathbf{b}}$} & \multicolumn{2}{c|}{$\mathbf{V}_{\mathbf{c}}$} \\
\cline { 2 - 7 } & {$[\mathbf{k V}]$} & {$[\mathbf{p u}]$} & {$[\mathbf{k V}]$} & {$[\mathbf{p u}]$} & {$[\mathbf{k V}]$} & {$[\mathbf{p u}]$} \\
\hline SE1 & 7.97 & 1.000 & 7.97 & 1.000 & 7.97 & 1.000 \\
\hline CG2 & 7.81 & 0.979 & 7.77 & 0.975 & 6.58 & 0.825 \\
\hline CG3 & 7.38 & 0.926 & 7.27 & 0.912 & 2.46 & 0.309 \\
\hline CG4 & 7.26 & 0.911 & 7.13 & 0.895 & 1.09 & 0.137 \\
\hline CG5 & 7.21 & 0.905 & 7.07 & 0.887 & 0.41 & 0.051 \\
\hline CG6 & 7.17 & 0.899 & 7.03 & 0.882 & 0.13 & 0.016 \\
\hline CG7 & 7.10 & 0.891 & 6.63 & 0.832 & 0.82 & 0.104 \\
\hline CG8 & 7.10 & 0.891 & 6.63 & 0.832 & 0.82 & 0.104 \\
\hline
\end{tabular}

Table VIII confirms that the short-circuit was applied at phase $\mathrm{C}$, once this phase has the lowest voltage values. It also indicates that all voltages magnitudes of busses CG6, CG7 CG8 reached the lowest values, when compared to pre-disturbance values, shown in Table VI.

With the occurrence of short-circuit, the substation supply changed to 16.7 MW of active power and 27.6 MVAr reactive power. The distributed generator provides 1.16 MW of active power and -1.37 MVAr of reactive power. The power behaviours of substation and DG can be seen, respectively, in Fig 2 and Fig 3.

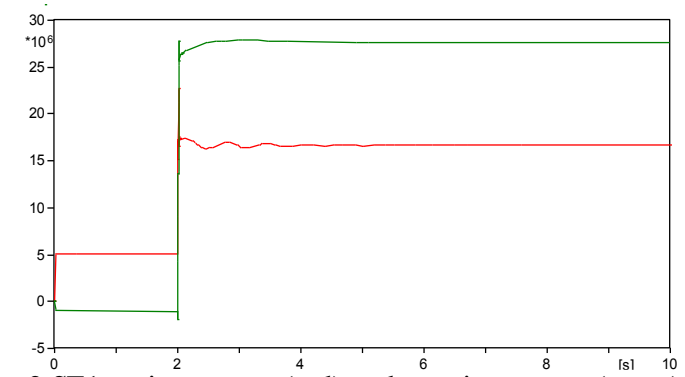

Fig. 2 SE1 active power (red) and reactive power (green) for short-circuit case with DG 


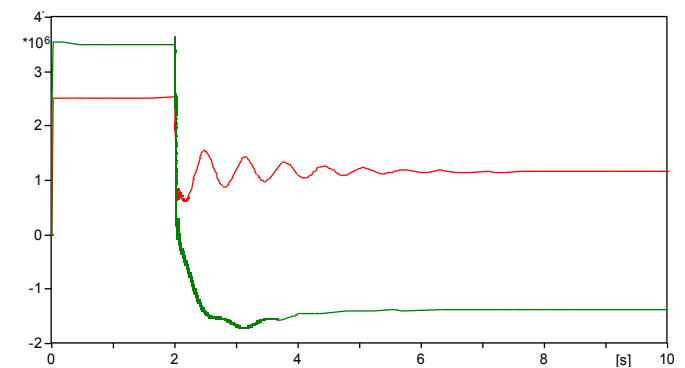

Fig. 3 DG active power (red) and reactive power (green) for short-circuit case with DG

To facilitate the comparisons, distributed generator was disconnected from the system and then applied the same disturbance. Table IX shows the final values after the disturbance ceases on all buses.

TABLE IX - Short-circuit case without DG: final steady-state voltage values

\begin{tabular}{|c|c|c|c|c|c|c|}
\hline \multirow{2}{*}{ Bus } & \multicolumn{2}{|c|}{$\mathbf{V}_{\mathbf{a}}$} & \multicolumn{2}{|c|}{$\mathbf{V}_{\mathbf{b}}$} & \multicolumn{2}{|c|}{$\mathbf{V}_{\mathbf{c}}$} \\
\cline { 2 - 7 } & {$[\mathbf{k V} \mathbf{V}]$} & {$[\mathbf{p u}]$} & {$[\mathbf{k V}]$} & {$[\mathbf{p u}]$} & {$[\mathbf{k V}]$} & {$[\mathbf{p u}]$} \\
\hline SE1 & 7.97 & 1.000 & 7.97 & 1.000 & 7.97 & 1.000 \\
\hline CG2 & 7.87 & 0.987 & 7.87 & 0.987 & 6.58 & 0.825 \\
\hline CG3 & 7.61 & 0.955 & 7.61 & 0.955 & 2.46 & 0.309 \\
\hline CG4 & 7.53 & 0.945 & 7.53 & 0.945 & 1.09 & 0.137 \\
\hline CG5 & 7.50 & 0.941 & 7.50 & 0.941 & 0.41 & 0.051 \\
\hline CG6 & 7.48 & 0.938 & 7.48 & 0.938 & 0.00 & 0.000 \\
\hline CG7 & 7.45 & 0.935 & 7.45 & 0.935 & 0.00 & 0.000 \\
\hline CG8 & 7.45 & 0.935 & 7.45 & 0.935 & 0.00 & 0.000 \\
\hline
\end{tabular}

Table IX indicates that voltage drops only in phase $\mathrm{C}$ and the same steady state voltage values are maintained in phases A and B (due to the infinite bus). Voltages at phase C of busses CG6, CG7 and CG8 became zero.

When the substation is the only responsible for the power supply to all system loads, it increases the steady-state values to 17.1 MW of active power and 24.2 MVAr of reactive power, as can be seen be seen in Figure 4.

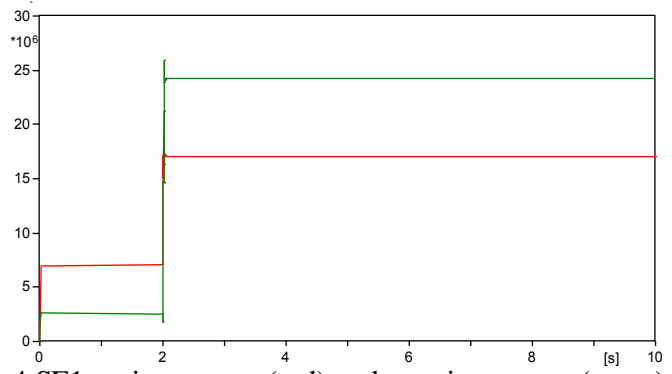

Fig. 4 SE1 active power (red) and reactive power (green) for short-circuit case without DG

\section{B. Islanding Case}

The islanding of the power system at time $2 \mathrm{~s}$ was the second disturbance considered in the simulations. The situation was achieved by opening the circuit-breaker on the output bus CG5, leaving loads CG6 and CG7 with total power of 2.77 MVA (2.64 MW and 0.84 MVAr) only provided by $5 \mathrm{MVA}$ distributed generator. Thus, this machine has enough capacity to supply power to islanded loads.
Table $\mathrm{X}$ presents the line voltage results after islanding, considering the distributed generator connected to the electrical system.

TABLE X - Islanding case with DG: final steady-state voltage values

\begin{tabular}{|c|c|c|}
\hline Bus & Voltage [k V] & Voltage [pu] \\
\hline SE1 & 13.80 & 1.000 \\
\hline CG2 & 13.70 & 0.993 \\
\hline CG3 & 13.45 & 0.975 \\
\hline CG4 & 13.39 & 0.970 \\
\hline CG5 & 13.37 & 0.969 \\
\hline CG6 & 13.78 & 0.999 \\
\hline CG7 & 13.80 & 1.000 \\
\hline CG8 & 13.80 & 1.000 \\
\hline
\end{tabular}

By looking at Table $\mathrm{X}$, it can be seen that the islanded busses, CG6, CG7 and CG8, have reached voltage values within the range limits established by the Brazilian regulations (ANEEL [13]).

After islanding, the substation provided $4.5 \mathrm{MW}$ of active power and 1.49 MVAr of reactive power, as shown in Fig. 5. On the other end, Fig. 6 indicates that the distributed generator supplied $3.08 \mathrm{MW}$ of active power and 0.78 MVAr of reactive power.

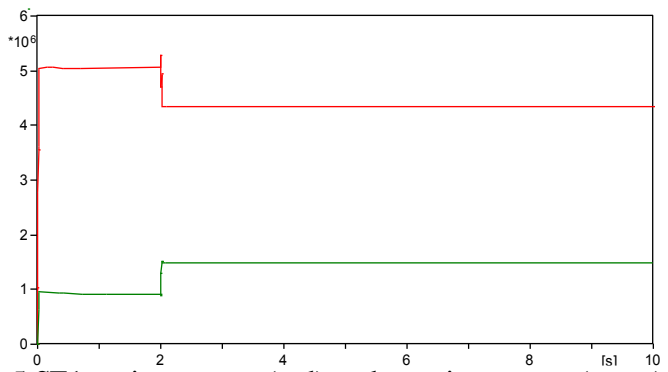

Fig. 5 SE1 active power (red) and reactive power (green) for islanding case with DG

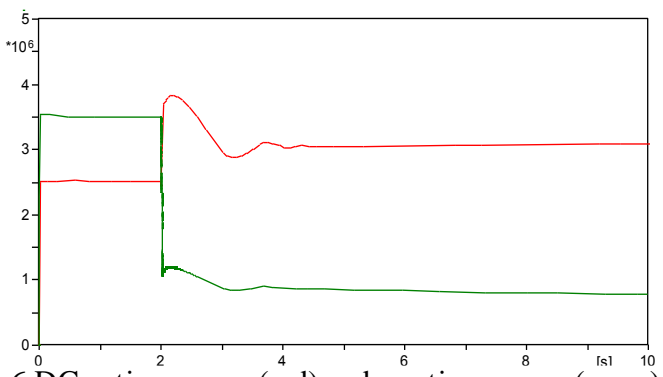

Fig. $6 \mathrm{DG}^{\mathrm{D}}$ active $^{2}$ power (red) and reactive power (green) for islanding case with DG

At this time, Table XI shows the line voltage results for the is landing case without the distributed generator

TABLE XI - Islanding case without DG: final steady-state voltage values

\begin{tabular}{|c|c|c|}
\hline Bus & Voltage [kV] & Voltage [pu] \\
\hline SE1 & 13.80 & 1.000 \\
\hline CG2 & 13.69 & 0.992 \\
\hline CG3 & 13.45 & 0.975 \\
\hline CG4 & 13.38 & 0.969 \\
\hline CG5 & 13.37 & 0.967 \\
\hline CG6 & 0.00 & 0.000 \\
\hline CG7 & 0.00 & 0.000 \\
\hline CG8 & 0.00 & 0.000 \\
\hline
\end{tabular}


Notice from Table XI that all loads located at busses after the disconnected branch (CG6, CG7 and CG8) lost their powers, that is, they were turned off. It can also be seen from Table XI that the voltages of the other busses have the similar values obtained with the presence of the distributed generator. After islanding, the substation supplied 4.35 MW of active power and 1.49 MVAr of reactive power, as depicted in Fig 7 below.

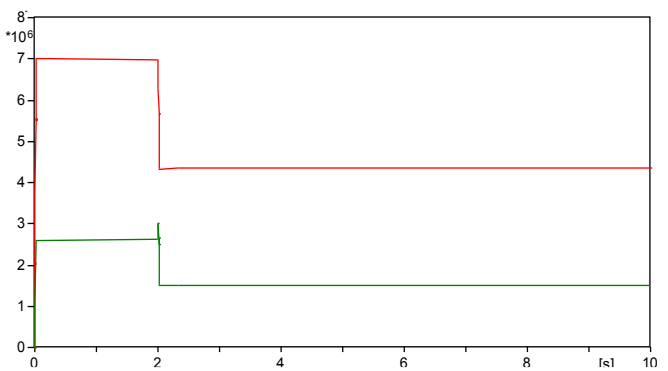

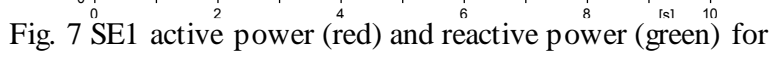
islanding case without DG.

\section{Load Increase Case}

An increase of load at CG8 distribution bus at time $2 \mathrm{~s}$ was the third phenomenon simulated. This new load was chosen to be $10 \%$ of the initial loading of the whole distribution system, or $673 \mathrm{~kW}$ of active power and 214 kVAr of reactive power. Such load was also modelled as previously described (by constant impedance).

Table XII shows the steady-state values of the line voltage after the load increase and taking into account the operation of the distributed generator.

TABLE XII- Load increase with DG: final steady-state voltage values

\begin{tabular}{|c|c|c|}
\hline Bus & Voltage [k V] & Voltage [pu] \\
\hline SE1 & 13.80 & 1.000 \\
\hline CG2 & 13.75 & 0.996 \\
\hline CG3 & 13.67 & 0.990 \\
\hline CG4 & 13.67 & 0.990 \\
\hline CG5 & 13.69 & 0.992 \\
\hline CG6 & 13.72 & 0.994 \\
\hline CG7 & 13.80 & 1.000 \\
\hline CG8 & 13.78 & 0.999 \\
\hline
\end{tabular}

The analysis of Table XII shows that even with the new load, the voltage values of all busses remained within the range recommended by ANEEL [13].

Figs 8 and 9 show the graph results for SE1 and DG supply powers, respectively.

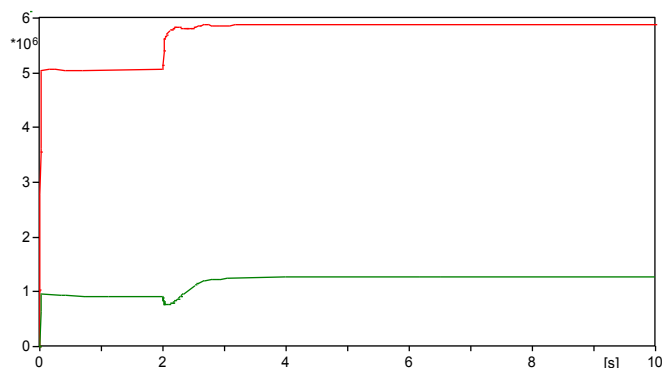

Fig. 8 Active power (red) and reactive power (green) in the SE1 electrical system with DG and with load increase.
Notice from Fig.8 that the substation raised its active power to $5.87 \mathrm{MW}$ and its reactive power to 1.28 MVAr. However, Fig.9 points that the distributed generator did not alter its initial active power (2.51 MW), but increased its reactive power to $4.19 \mathrm{MVAr}$, to ensure the nominal voltage at the bus.

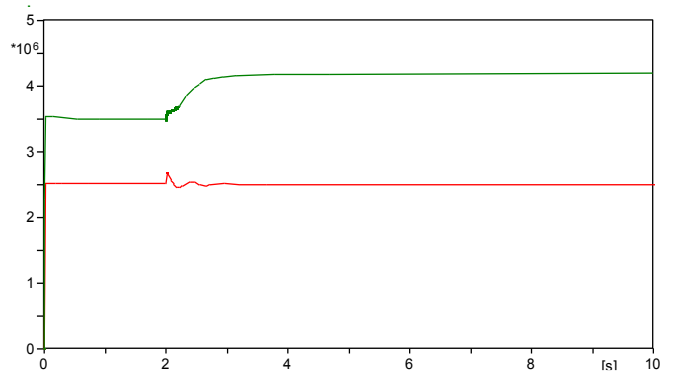

Fig. 9 Active power (red) and reactive power (green) of distributed generator with increased load.

If the same load increase is again simulated but now with the distributed generator out of operation, then, the steadystate values reached for the line voltages can be seen in Table XIII.

TABLE XIII - Load increase without DG: final steady-state voltage values

\begin{tabular}{|c|c|c|}
\hline Bus & Voltage [k V] & Voltage [pu] \\
\hline SE1 & 13.80 & 1.000 \\
\hline CG2 & 13.61 & 0.986 \\
\hline CG3 & 13.11 & 0.950 \\
\hline CG4 & 12.97 & 0.940 \\
\hline CG5 & 12.91 & 0.936 \\
\hline CG6 & 12.87 & 0.933 \\
\hline CG7 & 12.80 & 0.927 \\
\hline CG8 & 12.78 & 0.926 \\
\hline
\end{tabular}

The analysis of Table XIII shows that the line voltages were lower compared to those in Table XII. The largest voltage drop was $7.4 \%$ and occurred at bus CG8.

The active and reactive power supplied by the substation without the distributed generator rose to $7.63 \mathrm{MW}$ and 2.90 MVAr, respectively, as shown in Fig 10.

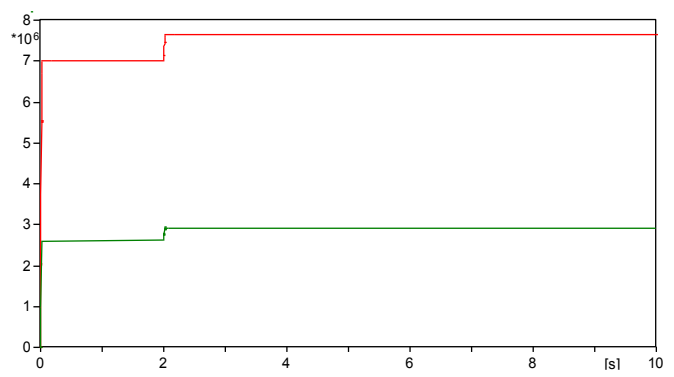

Fig. 10 SE1 active power (red) and reactive power (green) for load increase case without DG

\section{Conclusions}

The studies allowed to evaluate the impact of a distributed generator connected to a $13.8 \mathrm{kV}$ distribution feeder just after the occurrence of typical disturbances in the electrical system, such as phase-to-ground short-circuit, islanding of part of the system and load increase. 
The steady-state values obtained after the short-circuit simulation have obviously shown that, with the presence of the distributed generator, the voltages at phase $\mathrm{C}$ of busses CG6, CG7 and CG8 will never become null. Besides, with such generator, the substation will supply a lower active power and a higher reactive power.

In the islanding case, it was observed that the presence of the distributed generator was decisive in ensuring the supply of the isolated loads. The voltage magnitudes became close to rated values, since the total power thereof is lower than the nominal power of the distributed generator. The power supplied by the substation had the same value, either with or without the connection of the distributed generator.

The analysis of simulations, considering the load increase at the end of distribution line has pointed that voltage profile of all busses was better in the presence of the distributed generator than without it. The substation needs to supply a lower power when DG is on.

During normal operation, the distributed generator connected in the system reduces the power requirement from the substation. This fact contributes to the possibility of postponement or reduction of reinforcement work on the electrical system when new loads are added.

This work has performed several case studies concerned to the evaluation of medium voltage distribution network with/without distributed generation, using a simple electrical system. This was justified to get a better comprehension of the phenomena caused by the connection of a distributed generator to the distribution grid.

Future works will involve a more complex power system topology. In additions, comparisons with results presented by other researchers will also be conducted in order to improve and deep the acquired knowledge about this subject.

\section{Acknowledgement}

The authors acknowledge the funding support received from the Brazilian research agencies: CAPES, CNPq and FAPEMIG.

\section{References}

[1] S. Filho, "Análise Regulatória das Condições de nterconexão da Geração Distribuída: Requisitos para os Procedimentos de Distribuição", Dissertação (Mestre) Departamento de Engenharia Elétrica, Universidade Federal de Itajubá, Itajubá, 2005.

[2] E. S. Lora, J. Haddad, "Geração Distribuída - Aspectos Tecnológicos, Ambientais e Institucionais", Rio de Janeiro: Interciência, 2006.

[3] C. J. Mozina, "Impact of Green Power Distributed Generation," IEEE Industry Applications Magazine, July/Aug 2010.

[4] F. A. M. Moura; J. R. Camacho; M. L. R. Chaves, G. C. Guimarães. "Grid Integration of Renewable Sources in the Distribution Network: An Analysis Through ATP-EMTP". IEEE PES Conference on Innovative Smart Grid Technologies (ISGT 2012), 2012, Washington.

[5] L. M. Peres, M. L. R. Chaves, G. C. Guimarães, F. A. M. Moura, "A Computational Contribution to Analyse the Connection of an Independent Power Producer to the Grid', International Conference on Renewable Energies and Power Quality and Renewable Energy and Power Quality Journal, v.11, p.506, 2013.

[6] Resolução Normativa $N^{o}$ 482, 17 de Abril de 2012, Agência Nacional de Energia Elétrica, Abril de 2012.

[7] Procedimentos de Distribuição de Energia Elétrica no Sistema Elétrico Nacional (PRODIST): Módulo 3 -Acesso ao Sistema de Distribuição, Agência Nacional de Energia Elétrica, Dezembro de 2012.

[8] G. C. Guimarães, "Manual do UFUFlow: Programa de Fluxo de Carga (LoadFlow). Método de NewtonRaphson", Universidade Federal de Uberlândia, 2000.

[9] Catálogo, “Alumínio - Condutores Nus", Nexans.

[10] G. C. Guimarães, "Computer methods for transient stability analysis of isolated power generation systems with special reference to prime mover and induction motor modeling", PhD Thesis, University of Aberdeen, Scotland, GB 1990.

[11] P. M. Anderson, A. A. Fouad, "Power System Control and Stability", Second Edition. Iowa, IEEE Press, A John Wiley \& Sons, Inc., Publication, 2003.

[12] L. M. Peres, "Estudos do Desempenho Dinâmico de Geradores Síncronos de Produtores Independentes em Sistemas de Geração Distribuída via ATPDraw", Dissertação (Mestre) - Faculdade de Engenharia Elétrica, Universidade Federal de Uberlândia, Uberlândia, 2013.

[13] Procedimentos de Distribuição de Energia Elétrica no Sistema Elétrico Nacional (PRODIST): Módulo 8 Qualidade da Energia Elétrica, Agência Nacional de Energia Elétrica, Fevereiro de 2012. 